\title{
Attitudes towards people with disabilities: a systematic review of intervention effectiveness
}

\author{
Yuleinys A. Castillo $\left.{ }^{1 *}\right)$ Alan Larson ${ }^{2}$ \\ ${ }^{1}$ California State University, Fresno, USA \\ ${ }^{2}$ Stephen F. Austin State University, USA \\ ${ }^{*}$ Corresponding author, ఏe-mail: yuchas@aim.com
}

\begin{abstract}
The improvement of attitudes towards people with disabilities has led to studies focusing on the impact of interventions. This review systematically analyzes and synthesizes the use of interventions to influence attitudes toward people with disabilities. A comprehensive search was conducted across multiple databases to identify studies that used an intervention in English with a defined assessment instrument meant to measure attitudinal changes toward people with disabilities. Based on a literature research, 32 studies conducted in fourteen different countries were included. In the majority of the cases, the use of interventions was an effective tool to improve attitudes towards disabilities. Implications of findings for practitioners and researchers are discussed.
\end{abstract}

Keywords: Rehabilitation counseling, interventions, attitudes, disability, stigma, society.

How to Cite: Castillo, Y., \& Larson, A. (2020). Attitudes towards people with disabilities: a systematic Rreview of intervention effectiveness. COUNS-EDU: The International Journal of Counseling and Education, 5(2), 40-57. DOI: 10.23916/0020200526120

\section{Introduction}

People with disabilities often experience negative attitudes and discriminatory actions in society (Smart, 2009). Being a target of negative attitudes and behaviors can lead to feelings of loneliness, anxiety, and low self-worth (Marini \& Stebnicki, 2017). Additionally, prejudice, attitudinal barriers, and discrimination can limit the opportunities of people with disabilities in multiple areas including education (Rao, 2004), employment (Gilbride, Stensrud, Ehlers, Evans, \& Peterson, 2000; Taylor, Krane, \& Orkis, 2010), community integration (Verdonschot, de Witte, Reichrath, Buntinx, \& Curfs, 2009) and access to services (Krahn, Walker, \& Correa de Araujo, 2015). Therefore, rehabilitation professionals can assess negative attitudes and their impact on the experiences and integration of people with disabilities.

Negative perceptions toward disabilities, in general, can affect behaviors and attitudes towards people with disabilities at social and individual levels. Societal perceptions of disabilities can also lead to stigma that can affect equality and inclusion (Green, Davis, Karshmer, Marsh, \& Straight, 2005). Moreover, the societal stigmatization of disabilities can create substantial disparities in health, housing, employment, limited community life, and increased social distance (Werner, Corrigan, Ditchman, \& Sokol, 2012). Exposure to society's disability stigma can also result in self-stigma when a person with a disability internalizes a sense of prejudice and discrimination (Corrigan \& Kosyluk, 2014). As a result of self-stigma, people with disabilities may experience reduced self-esteem, empowerment, and hope, as well as show reluctance to participate in treatment, employment, and services (Livingston \& Boyd, 2010). Consequently, disability stigma can result in social disadvantages rooted in society as well as in the individual. 
These social and individual drawbacks, as a result of stigma, can vary for a variety of factors. The level of stigma varies depending on types of impairment, reason of disability onset, and severity of the condition. In a previous study, perceptions of parents and teachers on raising a child with disability, considering stigma and marginality, described two views of disability (Lalvani, 2015). Parents, using a social model, recognized cultural meanings ascribed to disability related to stigma, marginalization and access while teachers utilized a medical model to biologically define the experience of children with disability. In addition to perspective on disability from different models, stigma is on a spectrum that fluctuates depending on type of impairment. For instance, people with intellectual disabilities and mental illness tend to experience the most social inequalities and disparities in basic human rights due to stigma (Ditchman, Werner, Kosyluk, Corrigan, 2013). People with intellectual disabilities, severe mental health conditions, sensory disabilities, and albinism tend to experience more stigma than people with physical disabilities (Rohwerder, 2018).

In order to reduce the undesirable impact of negative attitudes on the quality of life of people with disabilities, a variety of social interventions have been implemented and tested to increase education and improve attitudes. For instance, educational projects that enhanced knowledge about disabilities (Kim, Park \& Snell, 2005; Tavares, 2011) as well as previous exposure to disability related information (Vignes el al., 2009) had been found to have a positive effect on students' attitudes regarding disabilities. Generally, education and contact interventions have been found to be the most effective approaches to change attitudes toward disabilities (Corrigan, Morris, Michaels, Rafacz, \& Rusch, 2012). Similarly, interventions used in different settings have been effective to diminish the impact of stigma on the perception of disabilities in society (Dunn, 2015).

\section{Interventions influence on changing attitudes}

People with disability face significant social challenges impacting their full participation and inclusion in society. Ableism relations, which are based on an ideal of normal and a division between "normal" human and subhuman, result in marginality and a perception of disability as problematic to community systems (Campbell, 2012). These negative interpretations of disability represent a complex barrier that creates oppression for people with disability resulting in ableism (Brown \& Broido, 2014). Moreover, ableist attitudes are multipart and may sometimes change slowly with a type of intervention.

Attitudes are considered to have three components, affect, cognition, and behavior, which may function as antecedents and consequences of attitudes (Olson, 1993). In other words, the three components can form attitudes but attitudes can also impact affect, cognitions, and behaviors. Additionally, attitudes impact the framework use to interpret environments and interactions with people with disabilities with a structured set of cognitions, relationships among those cognitions, and specific examples based on previous experiences (Fichten, 1994). Hence, attitudes can play a role in evaluating, interacting, and supporting people with disabilities.

Since changing attitudes can influence future behaviors, interventions represent an opportunity to increase positive attitudes towards people with disabilities. Attitudes can predict one's future behavior after a direct experience and information about the attitude object (Azjen, 2005). Disabilities become an attitude object that can influence one's behaviors and decisions. When individuals have negative attitudes towards disabilities, people with disabilities have limited opportunities of acceptance and educational engagement (Moore \& Nettelbeck, 2013). However, different interventions strategies have positively influence attitudes towards individuals with disabilities (Rabenschlag et al., 2012; Swaim \& Morgan, 2001) representing mechanism to foster accepting behaviors. Because of the predicting ability of behaviors, interventions focus on changing attitudes can change interactions and inclusion for people with disability.

Attitudinal interventions targeting disabilities have been utilized for many years to boost the quality of life of people with disabilities. In a systematic review, direct contact and indirect contact with people with disabilities were found as effective mechanisms to improve children's attitudes towards disability (MacMillan, Tarrant, Abraham, \& Morris, 2014). Similarly, education based interventions have also positive effects on attitudes towards disabilities using brief educational media (e.g. Lindau, Amin, Zambon, \& Scior, 2018), three weeks education projects (e.g. de Boer, Pijil, Minnaert, \& Post, 2014), and combined methods (e.g. Reina, Lopez, Jimenez, Garcia-Calvo, \& Hutzler, 2011). Equally, creative teaching interventions in a meta-analysis, as puppet shows, have led to changes in individuals' attitudes and knowledge of individual with disabilities (Dunst, 2014). 
Since interventions can help reduce the influence of stigma on the lives of people with disabilities, a systematic review of methods utilized to improve attitudes can assess effectiveness and provide potential options. Despite the research on interventions to improve attitudes toward disability has focused on strategies, the common elements of effective components can be synthesized. The aim of this review was to systematically review and synthesize the use of attitudinal interventions and how attitudes were changed toward people with disabilities using different strategies. This review intends to assist rehabilitation services professionals in identifying and understanding the implications of interventions in the inclusion and participation of people with disabilities. Understanding the significance of interventions is beneficial to intentionally incorporate strategies in services and social environments as well as increase disability intervention awareness. At the time of this study, other systematic reviews focused exclusively on children or focused on different parts of attitude changes; thus, this review specifically explored the utilization and success of different interventions to enhance attitudes toward disabilities.

\section{Method}

The approach used for this systematic review was an adapted version of a suggestion by BettanySlatnikov (2010a, 2010b), who recommends starting with an overall research question and then investigating populations, interventions, comparison of interventions, and outcomes. In this study, the overall research question is "how effective are interventions on changing attitudes toward people with disabilities?" The following supplemental research questions were also considered:

RQ1: Whose attitudes were attempted to be changed, and toward what types of disabilities?

RQ2: What interventions were used in attempting to change attitudes?

RQ3: What were the results of the interventions?

\section{Criteria for inclusion}

Studies included in this review evaluated interventions to change attitudes toward disabilities. For the purpose of this analysis, dissertations, literature reviews, conference papers, and book reviews were not included. Even though different interventions could help to improve attitudes, the focus was to evaluate studies performed using the English language with a clear measurement directed toward any type of disability. For consideration in this analysis, empirical studies published in peer-reviewed journals also had to involve participants in an intervention, measure attitudes toward disability, and take place in a community or educational setting.

\section{Identification process}

A systematic search was conducted using online library databases and the search engines of Academic Search complete, Psychology and Behavioral Sciences Collection, PsychINFO and PscyhARTICLES to find relevant peer-reviewed academic journal articles using the general search terms: attitude change, intervention, and disabilities. The systematic review of intervention studies focused on research published between 2005 and 2016. After eliminating any irrelevant or duplicate results, a total of 379 unique articles were generated. These peer-reviewed articles were then revised for the following inclusion criteria: 1) included an attitude change intervention, 2) able-bodied participants were the participants in the intervention, 3) the utilization of a qualitative and/or quantitative type of disability attitudes measurement 4) the study took place in a community or educational setting, and 5) written in English. Articles were excluded if they were about the psychometric properties of an instrument, were a meta-analysis, did not deal with specific attitudes about people with disabilities (i.e., attitudes about sex, diversity, inclusion, etc.), took place in a medical setting, or were about another unrelated topic. The end result was the total of 35 articles used in this analysis.

\section{Results}

\section{Overview of studies}

The full data set containing the results from all 35 studies can be found in table 1 . The studies identified in this analysis took place all over the world. The sample sizes ranged from 2 to 873 , and the age of the participants started from 7-years old into late adulthood. Specific answers to the research questions will be discussed in the next sections.

\section{Intervention population samples and disability types}


To answer the question of whose attitudes were attempted to be changed, we first categorized the studies by country. The United States had the most studies conducted in it, with $11(31.43 \%)$ while twelve (34.29\%) of the remaining studies were conducted in various countries in Europe, five (14.29\%) were conducted in the Middle East, three (8.57\%) were conducted in Canada, and two (5.71\%) were conducted in Africa, and remaining two (5.71\%) were conducted in India, and Australia.

Subsequently, we also divided the groups within the studies based on whose attitude was attempted to be changed. Overall, there were 41 different groups tested but some studies intervened with more than one type of group, thus there are more groups than studies. The most frequent intervention group was college students, with 20 (48.78\%). Eight (19.51\%) of the remaining groups were students in school, four $(9.76 \%)$ were various types of professionals already working with people with disabilities, another four $\mathbf{( 9 . 7 6 \% )}$ with the general public two $(4.88 \%)$ were with teachers, and three others $(7.32 \%)$ were mothers of children with intellectual disabilities, theme park employees, and wheelchair users due to a spinal cord injury.

To answer the question what disabilities were the object of attitude change, we grouped the specific disabilities listed in the studies into six broad disability categories. Because some studies measured the attitudes toward multiple types of disabilities, there were a total of 48 disabilities noted in the studies. The most frequently studied disability attitude was intellectual disabilities that included learning disabilities, with $15(31.25 \%)$, nine (18.75\%) were the disability population as a whole, eleven $(22.92 \%)$ were physical disabilities such as spinal cord injury, cerebral palsy, spina bifida, and muscular dystrophy, six (12.5\%) were on sensory disabilities such as vision and hearing impairments, another five (10.42\%) were mental disability such as mental illness and autism, and the remaining two (4.17\%) were Tourette's syndrome and communication disorders. The specific context of the results regarding used interventions for attitudinal change toward disabilities will be discussed in the next section.

\section{Interventions for attitudinal change}

To answer the question of what types of interventions were used to change attitudes, we organized the data first by category and then by study. We grouped the interventions into categories based on type of interventions. The interventions varied from formal education, contact, simulations, combined instruction, and community based approaches.

\section{Type of interventions.}

We next looked at the intervention data across studies. Of the 35 studies, 13 (37.14\%) combined instruction, which included any planned combination of formal instruction with contact or simulation, nine $(25.71 \%)$ used only formal education, seven $(20 \%)$ used only contact, two (5.71\%) focused on simulations, and one study each used teacher support, marketing, counseling, or a film festival (11.43\%). Each group of interventions aimed to change attitudes toward disabilities.

\section{Combined instruction.}

Thirteen studies combined formal instruction and a behavioral component. These studies aimed to blend a cognitive intervention, which prepare participants by learning about medical conditions and personal experiences prior to engaging in a behavioral activity (contact or simulation).

For instance, teachers in Cairo participated in 12 sessions (60 minutes each), combined with working and providing training to people with intellectual disabilities in sheltered workshops (Hassanein, 2015). In another study, medical students, in London, participated in a 14-week neurosciences course which included a three hour lecture on intellectual disabilities and an opportunity to participate in a threeweek placement at two learning disabilities services (Sinai et al., 2013).

Using contact theory as a theoretical framework, Wozencroft, Pate and Griffiths (2015) examined the impact of a service learning class on college students' attitudes toward people with disabilities. As part of this class, students received lecture material and worked directly with people with disabilities in a week long therapeutic camp environment. In another study involving graduate and undergraduate students, a course curriculum along online learning component, lectures, team based problem solving, and client interviews, were used to change knowledge, skills, and attitudes toward individuals with intellectual disabilities (ID) among healthcare students in Canada (Jones et al., 2015). To close the training, students participated in an interactive learning group to formulate a comprehensive assessment and treatment plan from the clinical vignettes. 
Five studies involved undergraduate students in different universities across the world. In a study in Ireland, undergraduate dental students enrolled in a comprehensive, blended learning program involving lectures, experiential workshops (i.e. observing dental procedures), and access to informational resources (Phadraig et al., 2015). In another study, undergraduate students received several preparatory lectures and seminars before interacting two to three times with a person with mild to moderate learning disabilities in a local day center or social enterprise unit (Smith \& Forrester-Jones, 2014). Fourth year undergraduate medical students participated in a three hour communication skills training session to improve interactions and reduce communication issues with patients with intellectual disabilities (Tracy \& Iacono, 2008). Finally, Israeli undergraduate social work students participated in a service learning program called Ripple Effect that included weekly interactions with people with disabilities (Zychlinski et al., 2016).

To change negative attitudes toward people with physical disability, ninth grade students in Germany participated in a cognitive intervention, which provided information and stereotypes about physical disability, and a behavioral intervention of engaging in three Paralympic disciplines under the instruction of athletes with disabilities (Krahe \& Altwasser, 2006). In Israel, middle school students without disabilities, who attended general education schools, participated in an inclusion program requiring 30-90 minute weekly or bi-weekly activities with students in special education classes (Marom et al., 2007). Students without disabilities received information about the specific disabilities prior interacting with students with disabilities in joint activities such as, sports, music, arts, volunteering, and social games. In another Israeli study, 9th grade students from various junior high schools participated in a school year long leadership integration program which combined information about disabilities with opportunities for contact with individuals with disabilities (Cohen et al., 2012). After four months in the program, the 9th grade students held workshops about prejudice, stigma, equal opportunities, and experiences with disabilities for the 8th grade students.

One study combined an educational component with a behavioral activity using simulation. Lewis (2011) used lecture-based awareness training and active impairment simulation activities to evaluate their influence on the attitudes of urban planning students in a Canadian university. The training event consisted of three lectures followed by a simulation exercise where the students wore prosthetic devices (e.g. leg braces), used mobility equipment (e.g. wheelchairs, crutches), or wore goggles. The lectures addressed general topics related to disability and impairment, and accessible planning and design. Another study used six digital brief interventions consisting of different combinations of education, indirect and imagine contact (Lindau, Amin, Zambon, \& Scior, 2017).

\section{Formal instruction}

Nine studies used a form of training to improve participants' attitudes toward disabilities. Two studies offered a workshop lasting from 90 minutes to one day. Tourism students in Slovenia participated in a 90 minute training covering material about social and psychological dimensions of disabilities as well as financial opportunities for businesses to generate profit in the growing market of customizing tourism for people with disabilities (Bizjak et al., 2011). In another study, a one-day disability awareness workshop was used to improve knowledge and attitudes toward guests with disabilities in theme parks (Hall, 2008). The workshop offered two sessions: one covering general issues about disability followed by a second session about specific disability areas, including origin of attitudes, strategies, double disability, among others.

As opposed to offering brief interventions, two studies opted for long educational engagements in academic settings. In Jordan, nursing students attended a course on mental health and pathology to improve attitudes toward people with mental illness (Hamaideh \& Mudallal, 2009). Finally, rehabilitation students, with different professional backgrounds and nationalities, completed a semester long program with seminars and lectures to establish a positive attitude toward disability and working with people with disability (Yazdani et al., 2016).

Another type of formal instruction used in five studies was the use of short videos about people with disabilities. In Ireland, school aged children were exposed to audiovisual material promoting inclusion for children with Down syndrome (Gannon \& McGilloway, 2009) while in the UK students watched a video on Paralympic athletes (Ferrara et al., 2015). Also in the UK, college students watched either a video of a rock band that included people with and without disabilities or a video about a hate crime committed against a person with an intellectual disability (Walker \& Scior, 2013). The other two studies were carried out in the United States. Flatt-Flutz and Phillips (2012) utilized a training video on empowerment of 
individual with intellectual and developmental disability for direct support professionals in human services. Lastly, Holtz and Tessman (2007) used short videos to increase elementary children's knowledge and improve attitude toward a peer with Tourette syndrome.

\section{Contact}

Seven studies used direct or indirect contact between participants and people with disabilities as an intervention to positively influence attitudes toward disabilities. In order to create an intervention that included equal-status contact and pursuit of common goals, Sullivan and Glidden (2014) required college swim team members to work together with Special Olympics swimmers to pursue swimming-related goals in 4 sessions over a 6-week period. In Canada, volunteering for 4 to 10 months with children with physical or hearing impairments was used to decrease social distance and improve attitudes (Fichten et al., 2005).

In another study, personal narratives, which can teach and influence emotions, written by individuals with complex communication needs, were used to change the attitudes of undergraduate business majors (McCarthy et al., 2010). Similarly, Galli et al. (2015) explored the influence of direct and indirect contact on attitudes toward wheelchair users. Participants were asked to interact with an individual with spinal cord injury in a 45-minute semi-structured conversation or to listen to a 45-minute audio about the experiences of wheelchair users. Equally, community based groups listened to adults with disabilities sharing their personal narratives (Gona, Newton, Hartley, \& Bunning, 2018).

Finally, a study in the United States used person-centered videos describing the life experiences of people with visible disabilities ( $\mathrm{Lu}$, Webber, Romero, \& Chirino, 2018). Staff, who provided services for adults with intellectual disabilities, participated in a half day training delivered by a trained professional and a person with an intellectual disability (ID) (Hutchinson et al., 2014). The Who's Challenging Who program incorporated two levels of contact with people with behavior challenges: direct contact with trainer with ID (valued position) and workshop material focused on people with ID and/or autism.

\section{Simulation}

Having participants act out being disabled for a period of time is considered simulation. In order to foster the development of positive attitudes toward persons with physical disability, Amosun, Wolmink and Rosin (2005) followed two South African students who registered in a 4-week special training module as part of their medical training. A role-playing exercise was used as a single, active learning intervention requiring to assume a mobility limitation and use a wheelchair for five consecutive working days. Students also maintained a journal to capture their everyday reflections about their simulation experience. Undergraduate student in an American university participated in a three-phase mixed method design involving simulation activities during an abroad study experience (McKenney, 2018).

\section{Sole interventions}

Four studies involved provided an intervention that required participants to engage in a variety of activities or aimed to affect society at large. In a study, Teachers in Science, Technology, Engineering Math (STEM) classes participated in a program educating students with visual impairments to increase awareness and provide funding for supplemental adaptive resources (Rule et al., 2011). In another study, Kirkwood and Stamm (2006) guided the design, distribution, and evaluation of an anti-stigma campaign regarding people with mental illness. A film festival was designed to provide authentic representation of people with disabilities living normal lives to help viewers see individuals with disabilities as people first (Schwartz et al., 2010). Lastly, counseling sessions were used to change attitudes of mothers of children with disabilities (Saravanan \& Rangaswamy, 2012). Next, outcomes of the interventions will be discussed.

\section{Intervention outcomes}

Some studies aimed to evaluate the utilization of interactive instruction type of interventions to improve attitudes toward people with disabilities. Wozencroft, Pate and Griffiths (2015) reported that students' attitudes positively changed after taking a course and remained constant after interacting with someone with a disability. The attitudes of students from different majors also positively changed when using interaction and education (Bizjak et ap., 2010; Lewis, 2011; McCarthy et al., 2010; Smith \& ForresterJones, 2014; Sullivan \& Glidden, 2014; Yazdani et al., 2016).

Five studies tried to evaluate the outcomes of work training interventions that positively influenced attitudes (Flatt-Fultz \& Phillips, 2012; Hall, 2008; Hutchinson et al., 2014; Hassanein, 2015; Rule et al., 2011). Communication training, simulation activities, and participation in a course helped improve attitudes toward disabilities among future medical professionals (Amosun et al., 2005; Hamaideh \& 
Mudallal, 2009; Jones et al., 2015; Tracy \& Iacono, 2008). Furthermore, a brief film-based digital intervention, showed to community based participants, had a small positive effects on attitudes to people with disabilities improved (Lindau et al., 2017). Likewise, videos with real-life experiences of people with visible disabilities positively influenced attitudes of undergraduate students (Lu et al., 2018).

In a couple of studies, involving adults (Fichten et al., 2005), volunteer contact as well as direct interaction with a wheelchair user, were effective in enhancing attitudes (Galli et al., 2015). Similarly, direct contact between middle school Israeli students without disabilities with those with disabilities helped to changed stereotypes (Cohen et al., 2012; Marom et al., 2007) as well as personal narratives improved recognition of the person and generated ideas for collective action in favor of disabilities (Gona et al., 2018). In another study, 9th grade students' attitudes positively changed as a result of leadership inclusion training and personal contact with people with disabilities (Cohen et al., 2012). Additionally, the use of visual media also led to positive changes among children and adults in small and large audiences (Holtz \& Tessman, 2007; Kirkwood \& Stamm, 2006; Schwartz et al., 2010).

In this review, four studies were identified as reporting no effect on attitudinal changes after implementing an intervention method with participants. In a study on school aged children, Gannon and McGilloway reported that girls tended to hold more favorable attitudes than boys toward children with learning disabilities (2009). Compared to other studies, they found that having a friend or relative with Down syndrome or watching an informative video about children with Down syndrome made no differences in attitudes toward disabilities among participants. Moreover, Phadraig et al. (2015) reported that dental students reported no difference in attitudes toward disabilities before or after participating in a brief blended learning program involving lectures, experiential workshops and access to resources. Sinai, Strydom and Hassiotis (2013) also reported that medical students had a better understanding of the definition of intellectual disability but there was no significant change in attitude after enrolling in the neurosciences course. Finally, participation in a service learning program was unsuccessful to lead to significant changes in attitude (Zychlinski et al., 2016). However, volunteering was correlated with negative attitudes toward disability while positive attitudes were significantly associated with prior positive attitudes among Israeli students. 
Table 1. Studies using interventions to change attitudes toward people with disabilities

\begin{tabular}{|c|c|c|c|c|}
\hline Study & $\begin{array}{l}\text { Intervention } \\
\text { Group }\end{array}$ & $\begin{array}{c}\text { Type of } \\
\text { Intervention }\end{array}$ & $\begin{array}{l}\text { Type of } \\
\text { Disability }\end{array}$ & Results \\
\hline $\begin{array}{l}\text { Amosun, S. L., Volmink, } \\
\text { L., \& Rosin, R. (2005) }\end{array}$ & $\begin{array}{l}2 \text { university medical } \\
\text { students in South Africa } \\
\text { (College) }\end{array}$ & $\begin{array}{l}\text { Five days of disability } \\
\text { simulation (Simulation) }\end{array}$ & $\begin{array}{l}\text { Physical disability - } \\
\text { wheelchair user(Physical) }\end{array}$ & $\begin{array}{l}\text { The two students reported } \\
\text { improved attitudes }\end{array}$ \\
\hline $\begin{array}{l}\text { Bizjak, B. Knezevic, M., } \\
\text { \& Cvetreznik, S. (2010) }\end{array}$ & $\begin{array}{l}124 \text { tourism students in } \\
\text { Slovenia (College) }\end{array}$ & $\begin{array}{l}\text { Two disability education } \\
\text { (Formal Instruction) }\end{array}$ & $\begin{array}{l}\text { Disability in general } \\
\text { (General) }\end{array}$ & $\begin{array}{l}\text { Both forms of education led to } \\
\text { improved attitudes }\end{array}$ \\
\hline $\begin{array}{l}\text { Cohen, R., Roth, D., } \\
\text { York, A., \& Neikrug, S. } \\
\text { (2012) }\end{array}$ & $\begin{array}{l}1649^{\text {th }} \text { grade students, } \\
\text { leadership program in } \\
\text { Israel (Pre-college) }\end{array}$ & $\begin{array}{l}\text { Compared education and } \\
\text { contact in a school year } \\
\text { (Combined Instruction) }\end{array}$ & $\begin{array}{l}\text { Intellectual } \\
\text { disabilities(Intellectual) }\end{array}$ & $\begin{array}{l}\text { Significant improvement in } \\
\text { attitudes among students }\end{array}$ \\
\hline $\begin{array}{l}\text { Ferrara, K., Burns, J., \& } \\
\text { Mills, H. (2015) }\end{array}$ & $\begin{array}{l}114 \text { college students in the } \\
\text { UK (College) }\end{array}$ & $\begin{array}{l}\text { Video of Paralympic and } \\
\text { Olympic performances } \\
\text { (Formal Instruction) }\end{array}$ & $\begin{array}{l}\text { Intellectual disabilities } \\
\text { (Intellectual) }\end{array}$ & $\begin{array}{l}\text { Both groups had improved } \\
\text { attitudes, and Paralympic media } \\
\text { had the greater improvement }\end{array}$ \\
\hline $\begin{array}{l}\text { Fichten, C. S., Schipper, } \\
\text { F., \& Cutler, N. (2005) }\end{array}$ & $\begin{array}{l}71 \text { new adult volunteers } \\
\text { in Canada (Volunteers) }\end{array}$ & $\begin{array}{l}\text { Working with children (4- } \\
\text { to } 10 \text { - month) (Contact) }\end{array}$ & $\begin{array}{l}\text { Children with physical or } \\
\text { hearing impairments } \\
\text { (HI)(Physical, Sensory) }\end{array}$ & $\begin{array}{l}\text { Attitudes toward both groups of } \\
\text { children improved with better } \\
\text { attitudes toward HI }\end{array}$ \\
\hline $\begin{array}{l}\text { Flatt-Fultz, E. \& Phillips, } \\
\text { L. (2012) }\end{array}$ & $\begin{array}{l}43 \text { direct support } \\
\text { professionals in the US } \\
\text { (Professionals) }\end{array}$ & $\begin{array}{l}\text { Empowerment video } \\
\text { (Formal Instruction) }\end{array}$ & $\begin{array}{l}\text { Intellectual and } \\
\text { developmental disabilities } \\
\text { (Intellectual, General) }\end{array}$ & $\begin{array}{l}\text { More empowering attitudes after } \\
\text { watching training video }\end{array}$ \\
\hline $\begin{array}{l}\text { Galli, G., Lenggenhager, } \\
\text { B., Scivoletto, G., } \\
\text { Molinar, M., \& } \\
\text { Pazzaglia, M. (2015). }\end{array}$ & $\begin{array}{l}85 \text { wheelchairs users, } \\
\text { physical therapists,people } \\
\text { w/o disabilities in Italy } \\
\text { (Professionals, Public, } \\
\text { Other) }\end{array}$ & $\begin{array}{l}\text { Interaction with } \\
\text { wheelchair user and audio } \\
\text { recording (Contact) }\end{array}$ & $\begin{array}{l}\text { Wheelchairs use due to a } \\
\text { spinal cord injury(Physical) }\end{array}$ & $\begin{array}{l}\text { Having direct contact increased } \\
\text { positive attitudes }\end{array}$ \\
\hline $\begin{array}{l}\text { Gannon, S. \& } \\
\text { McGilloway, S. (2009) }\end{array}$ & $\begin{array}{l}118 \text { 8-11 year old children } \\
\text { in Ireland (Pre-college) }\end{array}$ & $\begin{array}{l}\text { Lecture with supporting } \\
\text { media (Formal Instruction) }\end{array}$ & $\begin{array}{l}\text { Children with Down } \\
\text { syndrome(Intellectual) }\end{array}$ & $\begin{array}{l}\text { No significant improvement in } \\
\text { attitudes }\end{array}$ \\
\hline
\end{tabular}


Gona, J., Newton, C., Hartley, S., \& Bunning, K. (2018).

Hall, E.(2008)

Hamaideh, S. H. \&

Mudallal, R. (2009)

Hassanein, E. E. A.

Holtz, K. \& Tessman, G. (2007)

Hutchinson, L. M., Hastings, R. P., Hunt, P. H., Bowler, C. L., Banks, M. E., \& Totsika, V. (2012)

Jones, J., McQueen, M., Lowe, S., Minnes, P., \& Rishke, A. (2015)

Kirkwood, A. \& Stamm, B. H. (2006).
249 community members

Sub-Saharan Africa.

Personal narratives

(Contact)

40 theme park employees

in the US (Other)

193 nursing students in Jordan (College)

18 teachers in Egypt

(Teachers)

179 elementary school children US (Pre-college)

76 staff members at disability service related agencies in the UK (Professionals)

247 graduate students in Canada (College)

\section{1 community}

caregivers, gatekeepers, and teens in the US (Professionals, public)

A 1-day disability

Mental health \& pathology course Instruction) (Contact) Instruction) (Other)
Diverse disabilities awareness workshop (Formal Instruction) (Formal Instruction)

education and contact intervention (Combined

Video-based intervention (Formal Instruction)

Trained by a person with an intellectual disability

disabilities and/or autism(Intellectual, Mental)

Diverse type of disability. (General)

Mental illness(Mental)

Intellectual

disabilities(Intellectual)

Tourette Syndrome(Other) interview (Combined

Anti-stigma social media marketing campaign

Iintellectual disabilities (Intellectual)

Mental illness and the general disability population(Mental,
Improved recognition of PWD as fellow human beings.

Disability awareness workshop enhance knowledge and positive attitudes toward guests with disabilities

Attitudes improved four of the five subscales

Participation in educational and contact intervention improved attitudes

Video enhanced knowledge, positive attitudes, and behavioral intentions

Significant improvement in 3 of the 4 subscales (empowerment, selfefficacy, and empathy) General)
No significant change in attitudes

One year follow-up showed changes in attitudes and/or behaviors 
Krahe, B. \& Altwasser, C. $709^{\text {th }}$ grade students in (2006) Germany (Pre-college)

Lewis, J. L. (2011).

200 students in Canada (College)

Lindau, N., Amin, T., Zambon, A., \& Scior, K (2017).

Lu, J., Webber, W., Romero, D., \& Chirino, C. (2018)

Marom, M., Cohen, D., \& Naon, D. (2007)

McCarthy, J., DonofrioHorwitz, L., \& Smucker, L. (2010)

Mckenney, A. (2018).

Phadraig, C. M. G. (20) students in Ireland \& Timms, M. (2014) (College)

Rule, A., Stefanich, G., Boody, R., \& Peiffer, B. (2011)

15 science and mathematics teachers in the US (Teachers)

32 mothers of children with disabilities in India

Saravanan and

Rangaswamy (2012)
Training materials plus interaction (Combined Instruction)

Education \& simulation (Combined Instruction)

Education with contact (Combined Instruction)

Person-centered videos (contact)

Year-long information plus contact (Combined Instruction)

Reading personal narratives (Contact)

(Simulation) activity

Education and experiential activities (Combined Instruction)

Teacher support: adaptive consultation (Other)

Psychological counseling (Other) equipment and

Physical
disabilities(Physical)

Pysical \& visual (Physical, Sensory)

Intellectual Disability(ID)

Diverse disabilities

ID/Cerebral palsy(Intellectual, Physical)

\section{Communication} disorders(Other)

Physical \&

blindness(Physical/Sensory)

The general disability

population(General)

Visual

impairments(Sensory)
Only the intervention group had improved attitudes

Only the cognitive-behavioral (contact) intervention produced signification positive results

Interventions improved attitudes, educational intervention better

Small positive effects on attitudes.

Improved explicit attitudes

Reading narratives improved attitudes

positively affect people's attitudes and levels of empathy

No improvement in attitudes

Positive changes in attitudes among teachers in STEM classes.

Mother's attitudes became more positive towards their children with 
(Other)

Schwartz et al., (2010)

107 graduate students, faculty, and community members in the US (College)

Sinai, A., Strydom, A., \& 133 medical students in Hassiotis, A. (2013). the UK (College)

62 undergraduate students learning disabilities in the UK (College)

Jones, R (2014)

Sullivan, E., \& Glidden, L. (2014).

Tracy, J., \& Iacono, T. (2008).

33 college swim team members in the US (College)

128 undergraduate premedical students in Australia (College)

Walker, J, \& Scior, K. (2013).

403 College students in the UK (College)

Wozencroft, A., Pate, J., 84 students in a service \& Griffiths, H. (2015). learning class in the US (College)

Yazdani, N., Yazdani, F., 14 students in a \& Nobakht, L. (2016)
14 students in a
rehabilitation master's
Film festival (Other)

14-week neurosciences course plus clinical placement (Combined Instruction)

Lectures plus two to three contacts (Combined Instruction)

Swim program with Special Olympic swimmers (Contact)

Contact plus education

(Combined Instruction)

\section{0-minute film (Formal Instruction)}

Contact plus education (Combined Instruction)

Semester long lecture (Formal Instruction) intellectual disability

Cerebral palsy, autism, \& developmental disabilities(General)

Intellectual and learning disabilities (Intellectual)

Mild to moderate learning disabilities(Intellectual)

Intellectual and developmental disabilities(Intellectual)

ID, with some physical and/or sensory

disabilities(Intellectual, Physical, Sensory)

\section{Intellectual}

disabilities(Intellectual)

Diverse disability(Physical, Sensory, Mental)

The general disability population (General)
Film can help to foster positive disabilities

Medical students increased knowledge of definitions and favorable attitude towards people with ID but there was no significant change in attitude

Change of attitude towards people with learning disabilities after experiencing direct contact

Participation in program increased positive attitudes

Significant positive change in attitude, better understanding and more comfortable feeling

Changed inclusion attitudes and social distance

Significant change in attitudes at the end of the course

Students became more accepting of people with disabilities 
COUNS-EDU

The International Journal of Counseling and Education

Vol.5, No.2, 2020

program, UK (College)

Zychlinski, E., Ben-Ezla, 150 social work students

M., \& Raz, Y. . (2016).

in Israel (College)

Service learning course plus contact (Combined Instruction)
The general disability population (General)
No significant overall change in attitude.

Studies are alphabetically sorted - Category in parentheses 


\section{Implications}

This systemic review identified 35 articles about intervention methods to change attitudes toward disabilities among different groups of individuals. In this review, most interventions were found to improve attitudes towards people with disabilities. Professionals in the rehabilitation field would benefit from an understanding of the impact of interventions on attitudes and awareness about the harmful experience of those with disabilities in society. The research on these interventions demonstrated effective approaches to reduce attitudinal barriers toward people with disabilities.

Of the 35 studies included, 31 showed a positive attitudinal change among participants, and just four showed no changes in perceptions, behaviors or attitudes. Only Gannon and McGilloway (2009), Phadraig et al. (2015), Sinai, Strydom and Hassiotis (2013), and Zychlinski et al. (2016) identified no changes in attitudes. All the studies with positive results suggest that interventions increase awareness and perspectives on the experience of those with disabilities in society. For instance, participants explained that the experience of being in a wheelchair led to negative social interactions and physical barriers, which then caused feelings of inferiority and lowered self-esteem (Amosun et al., 2005). An increased sense of awareness could help to positively change current misperceptions and improve attitudes towards people with disabilities (Burke et al., 2013)

The majority of the studies (24) were carried out in many countries around the world with eleven in the United States. While most people in the United States may seem to agree with the rights of people with disabilities, there is still discrimination and prejudice experienced by people with disabilities (Smart, 2009). Globally, social and legislative changes have also attempted to reduce discrimination towards people with disabilities. Efforts to change stigma toward disabilities have been found to be effective, suggesting that contact between the general public and people with disabilities may positively change prejudicial attitudes, especially mental illness stigma (Corrigan \& Penn, 2015). Using interventions toward disabilities would likely decrease negative attitudes, thus potentially improving the quality of life and social inclusion of people with disabilities. These findings support evidence based practices that can be used by rehabilitation professionals to decrease stigma toward disabilities.

If, as appears to be the case in this review, attitude intervention in all its various forms is almost always successful in improving attitudes, rehabilitation professionals and researchers should consider ways to incorporate these methods into practice. Knowledge and contact seem useable tools to influence attitudes in a variety of interventions. The findings reported by Fichten et al (2005) exemplified how volunteer contact had a great impact on reducing social distance while improving self-focused views of attitudes, comfort, and thoughts about disabilities, including more favorable views about people who have a hearing impairment. Rehabilitation professionals and researchers can use information to increase knowledge and promote contact as useable tools to influence attitudes in a variety of social and educational settings.

Contact can help to improve attitudes but having people with and without disabilities work together to achieve a common goal can have long term impact on attitudes (Johnson, 2006). Rehabilitation professionals can structure activities with consumers and employers as part of the rehabilitation process. In the work settings, rehabilitation professionals and clients with disabilities work together but collaboration on goal achievement can offer opportunities to decrease prejudice and stigma toward disabilities. Stigma can hinder goal attainment; however, involvement in evidence-based practices supports the achievement of life goals and reduces negative attitudes toward disability (Corrigan, Larson, \& Rusch, 2009). Therefore, collaboration between stakeholders involved in the rehabilitation process - consumer, professionals, employers, among others -can contribute to promote inclusion and positive views of disabilities.

Nonetheless, Sinai, Strydom and Hassiotis (2013) suggested that didactic teaching and limited exposure to people with intellectual disabilities increases knowledge but may not be enough to improve attitudes. With this finding, rehabilitation professionals and employers might want to assess their audience to determine a feasible intervention before assuming that just any intervention would be effective in attitudinal changes. In order to effectively generate a potential positive shift in attitude toward disabilities, rehabilitation professionals need to evaluate each intervention separately. While assessing the intervention for attitudinal change, the rehabilitation professional should consider the cognitive ability, developmental stage, emotional readiness, previous experiences, and motivation of the targeted audience. These considerations can increase the effectiveness of the applied intervention to reach the goal of enriched quality of life for people with disabilities. 
Although this systemic review contributes to the value of interventions to change attitudes, there are some important methodological limitations. The search utilized only relevant databases and not a review of reference lists, as recommended by Bettany-Slatnikov (2010a, 2010b). Since it could be difficult to review each potential study, there is possible human error for excluding a feasible study. Due to discovering the ubiquity of international research on attitude intervention, the resulting 35 articles analyzed in this review were deemed representative, if not exhaustive. Another limitation is that the evidence comes mainly from cross-sectional attitude surveys using convenience and student samples. Results should be interpreted with reasonable caution considering potential methodological limitation and external factors that could influence the outcomes. Since $88 \%$ of the participant samples in this review showed a positive change in attitudes after being part of an intervention, rehabilitation professionals and instructors should keep these approaches in mind as an area of concern and attitudinal transformation.

It is recommended that future research should migrate from attitude intervention with small samples to broader inquiries into what effect improved attitudes have on societal inclusion of people with disabilities. Furthermore, research could also continue to assess interventions in community and vocational settings (Bartram \& Cavanagh, 2019) as well as interaction focus on the human-animal bond (Silcox, Castillo, \& Reed, 2014). Some of the studies reached larger audiences in public settings leading to a positive attitudinal change that could translate into opportunities for marginalized groups, improved policy, and voices for advocacy. As example of potential community impact, Kirkwood and Stamm (2006) explained that even though attitude changes were minimal in their study of Idaho citizens, the mild decreases in stigma and increases in awareness of mental health services resulted in a rise in referrals for children with mental disorders. In addition, research could also evaluate external and internal factors to better identify ways to change attitudes toward disabilities with short and long term impact including vocational interventions.

\section{Conclusions}

Therefore, a valuable contribution of this research supports that interventions can change attitudes towards disability fostering inclusion, equity opportunities, and quality of life. There seems to be an implicit understanding that interventions can enhance attitudes towards disabilities decreasing barriers and increasing social connections. Results highlight the role of attitudinal intervention with potential implication in vocational, recreational, social, and political arenas for people with disabilities.

\section{References}

Amosun, S. L., Volmink, L., \& Rosin, R. (2005). Perceived images of disability: The reflections of two undergraduate medical students in a university in South Africa on life in a wheelchair. Disability and Rehabilitation, 27(16), 961-966. http://doi.org/10.1080/09638280500030407

Bartram, T., \& Cavanagh, J. (2019) Re-thinking vocational education and training: Creating opportunities for workers with disability in open employment. Journal of Vocational Education \& Training, 71(3), 339349, DOI: $10.1080 / 13636820.2019 .1638168$

Bettany-Saltikov, J. (2010a). Learning how to undertake a systematic review: Part 1. Nursing Standard, 24(50), 47-55. http://doi.org/10.7748/ns2010.08.24.50.47.c7939

Bettany-Saltikov, J. (2010b). Learning how to undertake a systematic review: Part 2. Nursing Standard, 24(51), 47-56. http://doi.org/10.7748/ns2010.08.24.50.47.c7939

Bizjak, B., Knezevic, M., \& Cvetreznik, S. (2011). Attitude change toward guests with disabilities. Reflections from Tourism Students. Annals of Tourism Research, 38(3), 842-857. http://doi.org/10.1016/j.annals.2010.11.017

Burke J., Bezyak, J., Fraser, R.T., Pete, J., Ditchman, N., \& Chan, F. (2013) Employers' attitudes toward hiring and retaining people with disabilities: A review of the literature. The Australian Journal of Rehabilitation Counseling, 19(1), 21-38.

Campbell F.K. (2012) Stalking Ableism: Using Disability to Expose 'Abled' Narcissism. In: Goodley D., Hughes B., Davis L. (eds) Disability and Social Theory. Palgrave Macmillan, London. 
A.

Cohen, R., Roth, D., York, A., \& Neikrug, S. (2012). Youth leadership program for changing self-image and attitude toward people with disabilities. Journal of Social Work in Disability \& Rehabilitation, 11(3), 197-218. http://doi.org/10.1080/1536710X.2012.704215

Corrigan, P.W., \& Kosyluk, K.A. (2014). Mental illness stigma: Types, constructs and vehicles for changeIn P.W. Corrigan (Ed.), The stigma of disease and disability: Understanding causes and overcoming (pp.35-56). Washington, DC, US: American Psychological Association.

Corrigan, P. W., Larson, J.E., \& Rusch, N. (2009). Self-stigma and they "why try" effect: Impact on life goals and evidence-based practices. World Psychiatry, 8(2), 75-81.

Corrigan, P.W., Morris, S.B., Michaels, P.J., Rafacz, J.D., \& Rusch, N. (2012). Challenging the public stigma of mental illness: A meta-analysis of outcome studies. Psychiatric Services, 63, (10), 963-973.

Corrigan, P.W., \& Penn, D. L.(2015). Lessons from social psychology on discredting psychiatric stigma. Stigma and Health, 1(S), 2-17).

Ditchman N., Werner, S., Kosyluk K., \& Corrigan, P. (2016). Stigma and Intellectual Disability: Potential application of Mental Illness research. Rehabilitation Psychology, 58(2), 206-216.

de Boer, A., Pijl, S. J., \& Minnaert, A. (2012). Students' attitudes toward peers with disabilities: A review of the literature. International Journal of Disability Development and education, 59(4), 379-392. dot: 10.1080/1034912X.2012.723944

de Boer, A., Pijl, S. J., Minnaert, A., \& Post, W. (2014). Evaluating the effectiveness of an intervention program to influence attitudes of students towards peers with disabilities. Journal of Autism and Developmental Disorders, 44(3), 572-583. doi:10.1007/s10803-013-1908-6

Dunst, C. J. (2014). Meta-analysis of the effects of puppet shows on attitudes toward and knowledge of individuals with disabilities. Exceptional Children, 80(2), 136-148. doi:10.1177/001440291408000201

Ferrara, K., Burns, J., \& Mills, H. (2015). Public attitudes toward people with intellectual disabilities after viewing olympic or paralympic performance. Adapted Physical Activity Quarterly, 32(1), 19-33. http://doi.org/10.1123/apaq.2014-0136

Fichten, C. S., Schipper, F., \& Cutler, N. (2005). Does volunteering with children affect attitudes toward adults with disabilities? A prospective study of unequal contact. Rehabilitation Psychology, 50(2), 164173. http://doi.org/10.1037/0090-5550.50.2.164

Flatt-Fultz, E., \& Phillips, L. A. (2012). Empowerment training and direct support professionals' attitudes about individuals with intellectual disabilities. Journal of Intellectual Disabilities: JOID, 16(2), 119-25. http://doi.org/10.1177/1744629512443652

Galli, G., Lenggenhager, B., Scivoletto, G., Molinari, M., \& Pazzaglia, M. (2015). Don't look at my wheelchair! The plasticity of longlasting prejudice. Medical Education, 1239-1247. http://doi.org/10.1111/medu.12834

Gannon, S., \& McGilloway, S. (2009). Children's attitudes toward their peers with Down Syndrome in schools in rural Ireland: An exploratory study. European Journal of Special Needs Education, 24(4), 455463. http://doi.org/10.1080/08856250903223104

Gilbride, D., Stensrud, R., Ehlers, C., Evans, E., \& Peterson, C. (2000). Employers' attitudes toward hiring persons with disabilities and vocational rehabilitation services. Journal of Rehabilitation, 66(4), $17-23$.

Gona, J., Newton, C., Hartley, S., \& Bunning, K. (2018). Persons with disabilities as experts-by experience: Using personal narratives to affect community attitudes in Kilifi, Kenya. BMC International Health and Human Rights, 18(1), 18.

Green, S., Davis, C., Karshmer, E., Marsh, P., \& Straight, B.(2005). Living stigma: The impact of labeling, stereotyping, separation, status loss, and discrimination in the lives of individuals with disabilties and their families. Sociaological Inquiry, 75(2), 197-463.

Hall, E. W. (2008). Changing the way guests interact with guests with disabilities. Journal of Disability 
Policy Studies, 19(1), 15-23.

Hamaideh, S. H., \& Mudallal, R. (2009). Attitudes of Jordanian nurding students toward mental illness: The effect of teaching and contact on attitudes change. College Student Journal, 43(2), 335-346.

Hassanein, E. E. (2015). Changing teachers' negative attitudes toward persons with intellectual disabilities. Behavior Modification, 39(3), 367-389. http://doi.org/10.1177/0145445514559929

Holtz, K. D., \& Tessman, G. K. (2007). Evaluation of a peer-focused intervention to increase knowledge and foster positive attitudes toward children with Tourette syndrome. Journal of Developmental and Physical Disabilities, 19(6), 531-542. http://doi.org/10.1007/s10882-007-9042-z

Hutchinson, L. M., Hastings, R. P., Hunt, P. H., Bowler, C. L., Banks, M. E., \& Totsika, V. (2014). Who's Challenging Who? Changing attitudes toward those whose behaviour challenges. Journal of Intellectual Disability Research, 58(2), 99-109. http://doi.org/10.1111/j.1365-2788.2012.01630.x

Johnson, M. (2006). Disability awareness: Doing it right. Louisville, KY: Avocado Press.

Jones, J., McQueen, M., Lowe, S., Minnes, P., \& Rischke, A. (2015). Interprofessional education in Canada: Addressing knowledge, skills, and attitudes concerning intellectual disability for future healthcare professionals. Journal of Policy and Practice in Intellectual Disabilities, 12(3), 172-180. http://doi.org/10.1111/jppi.12112

Kim, J., Park, E., \& Snell, M. E. (2005). Impact of information and weekly contact on attitudes of Korean general educators and nondisabled students regarding peers with disabilities. Mental Retardation, 43(6), 401-415.

Kirkwood, A. D., \& Stamm, B. H. (2006). A social marketing approach to challenging stigma. Professional Psychology: Research and Practice, 37(5), 472-476. http://doi.org/10.1037/0735-7028.37.5.472

Krahe, B., \& Altwasser, C. (2006). Changing negative attitudes toward persons with physical disabilities: An experimental intervention. Journal of Community and Applied Social Psychology, 16(1), 59-69. http://doi.org/10.1002/casp.849

Krahn, G. L., Walker, D. K., \& Correa-De-Araujo, R. (2015). Persons with disabilities as an unrecognized health disparity population. American Journal of Public Health, 105(S2), S198-S206. doi:10.2105/AJPH.2014.302182

Lewis, J. L. (2011). Student attitudes toward impairment: An assessment of passive and active learning methods in urban planning education. Teaching in Higher Education, 16(2), 237-249. http://doi.org/10.1080/13562517.2010.524921

Lindau, N., Amin, T., Zambon, A., \& Scior, K. (2018). The effect of Brief Digital Interventions on attitudes to Intellectual Disability: Results from a pilot study. Journal of Applied Research in Intellectual Disabilities, 31(1), 106-113.

Livingston, J. D., \& Boyd, J.E. (2010). Correlates and consequences of internalized stigma for people with mental illness: A systematic review and meta-analysis. Social Science \& Medicine, 71, 2150-2061.

Lu, J., Webber, W., Romero, D., \& Chirino, C. (2018). Changing attitudes toward people with disabilities using public media: An experimental study. Rehabilitation Counseling Bulletin, 61(3), 175-186.

MacMillan, M., Tarrant, M., Abraham, C., \& Morris, C. (2014). The association between children's contact with people with disabilities and their attitudes towards disability: A systematic review. Developmental Medicine \& Child Neurology, 56(6), 529-546. doi:10.1111/dmcn.12326

Marini, I., \& Stebnicki, M. A. (Eds.). (2017). The psychological and social impact of illness and disability (7th ed.). New York, NY.: Springer.

Marom, M., Cohen, D., \& Naon, D. (2007). Changing disability- related attitudes and self- efficacy of Israeli children via the Partners to Inclusion Programme. International Journal of Disability, Development and Education, 54(1), 113-127. http://doi.org/10.1080/10349120601149821

McCarthy, J. W., Donofrio-Horwitz, L. M., \& Smucker, L. M. D. (2010). The effects of reading personal narratives written by an individual who uses AAC on the attitudes of pre-professionals in business. Augmentative and Alternative Communication (Baltimore, Md.: 1985), 26(2), 61-74. 
A.

http://doi.org/10.3109/07434618.2010.481562

McKenney, A. (2018). Attitude changes following participation in disability simulation activities. Therapeutic Recreation Journal, 52(3), 215-236.

Moore, D., \& Nettelbeck, T. (2013). Effects of short-term disability awareness training on attitudes of adolescent schoolboys toward persons with a disability. Journal of Intellectual \& Developmental Disability, 38(3), 223-231. doi:10.3109/13668250.2013.79053

Phadraig, C. M. G., Nunn, J. H., Tornsey, O., \& Timms, M. (2015). Does special care dentistry undergraduate teaching improve dental student attitudes toward people with disabilities? European Journal of Dental Education, 19(2), 107-112. http://doi.org/10.1111/eje.12110

Rabenschlag, F., Schusterschitz, C., Conca, A., Knuf, A., Needham, I., \& Hoffmann, H. (2012). Influence of single peer interventions on the recovery attitude of persons with a psychiatric disability. Scandinavian Journal of Caring Sciences, 26(4), 755-760. doi:10.1111/j.1471-6712.2012.00995.x

Rao, S.(2004). Faculty attitudes and students with disabilities in higher education: A literatura review. College Student Journal, 38(2), 191-198.

Reina, R., López, V., Jiménez, M., García-Calvo, T., \& Hutzler, Y. (2011). Effects of awareness interventions on children's attitudes toward peers with a visual impairment. International journal of rehabilitation research. Internationale Zeitschrift fur Rehabilitationsforschung. Revue internationale de recherches de readaptation, 34(3), 243.

Rose, J., Gallivan, A., Wright, D., \& Blake, J. (2014). Staff training using positive behavioural support: The effects of a one-day training on the attributions and attitudes of care staff who work with people with an intellectual disability and challenging behaviour. International Journal of Developmental Disabilities, 60(1), 35-42. http://doi.org/10.1179/2047387713Y.0000000020

Rule, A. C., Stefanich, G. P., Boody, R. M., \& Peiffer, B. (2011). Impact of adaptive materials on teachers and their students with visual impairments in secondary science and mathematics classes.International Journal of Science Education, 33(6), 865-887. http://doi.org/10.1080/09500693.2010.506619

Saravanan, C., \& Rangaswamy, K. (2012). Effectiveness of counselling on the attitudes of mothers toward their children with intellectual disability. Asia Pacific Journal of Counselling and Psychotherapy, 3(1), 8294. http://doi.org/10.1080/21507686.2011.648648

Schwartz, D., Blue, E., McDonald, M., Giuliani, G., Weber, G., Seirup, H., .. Perkins, A. (2010). Dispelling stereotypes: Promoting disability equality through film. Disability \& Society, 25(7), 841-848. http://doi.org/10.1080/09687599.2010.520898

Silcox, D., Castillo, Y.A., \& Reed, B. (2014). The Human-animal bond: Applications for rehabilitation professionals. Journal of Applied Rehabilitation Counseling, 45(3), 27-37.

Sinai, A., Strydom, A., \& Hassiotis, A. (2013). Evaluation of medical students attitudes toward people with intellectual disabilities: A naturalistic study in one medical school. Advances in Mental Health and Intellectual Disabilities, 7, 18-26. http://doi.org/10.1108/20441281311294666

Smart, J. (2009). Disability, society, and the individual (2nd ed.). Austin, TX: Pro-Ed.

Smith, C., \& Forrester-Jones, R. (2014). Experiential learning: Changing student attitudes toward learning disability. Tizard Learning Disabilities Review, 19(3), 110-117.

Sullivan, E., \& Glidden, L. M. (2014). Changing attitudes toward disabilities through unified sports. Intellectual and Developmental Disabilities, 52(5), 367-378. http://doi.org/10.1352/1934-9556-52.5.367

Swaim, K. F., \& Morgan, S. B. (2001). Children's attitudes and behavioral intentions toward a peer with autistic behaviors: Does a brief educational intervention have an effect? Journal of Autism and Developmental Disorders, 31(2), 195-205.

Tavares, W. (2011). An evaluation of the Kids are Kids disability awareness program: Increasing social inclusion among children with physical disabilities. Journal of Social Work in Disability and Rehabilitation, 10, 25-35. 
Taylor, H., Krane, D., \& Orkis, K. (2010). The ADA, 20 years later. New York: Harris Interactive (conducted for the Kessler Foundation and National Organization on Disability).

Tracy, J., \& Iacono, T. (2008). People with developmental disabilities teaching medical students--does it make a difference? Journal of Intellectual \& Developmental Disability, 33(January 2015), 345-348. http://doi.org/10.1080/13668250802478633

Verdonschot, M.M., de Witte, L.P., Reichrath, E., Buntinx, W.H., \& Curfs, L.M. (2009). Community participation of people with an intellectual disability: A review of empirical findings. Journal of Intellectual Disability Research, 53(4), 303-318.

Vignes, C.V., Godeau, E., Sentenac, M., Coley, N., Navarro, F., Grandjean, H., \& Arnaud. C. (2009). Determinants of students' attitudes toward peers with disabilities. Developmental Medicine and Child Neurology 51, 473-479. doi: 10.1111/j.1469-8749.2009.03283.x.

Walker, J., \& Scior, K. (2013). Tackling stigma associated with intellectual disability among the general public: A study of two indirect contact interventions. Research in Developmental Disabilities, 34(7), 2200-2210. http://doi.org/10.1016/j.ridd.2013.03.024

Werner, S., Corrigan, P., Ditchman, N., \& Sokol, K. (2012). Stigma and intellectual disability: A review of measures and future directions. Research in Developmental Disabilities, 33,748-65. doi:10.1016/j.ridd.2011.10.009

Wozencroft, A. J., Pate, J. R., \& Griffiths, H. K. (2015). Experiential learning and Its impact on students' attitudes toward youth With disabilities. Journal of Experiential Education, 38(2), 129-143. http://doi.org/10.1177/1053825914524363

Yazdani, N., Yazdani, F., \& Nobakht, L. (2016). Reflective self-awareness exercise; steps toward changing students' attitudes toward disability. International Journal of Therapies and Rehabilitation, 5(2). http://doi.org/10.5455/ijtrr.000000122

Zychlinski, E., Ben-Ezra, M., \& Raz, Y. H. (2016). Changing attitudes about disability: The impact of the "Accessible Community" program. Journal of Socail Work, 16(6), 742-757. http://doi.org/10.1177/1468017315589871 